Erratum

\title{
Erratum to: Experimental Research and Numerical Simulation of a Large-spanIsolated Structure Considering Multi-dimensional Input Effects
}

\author{
Zhen-yuan Gu, Shu-guang Wang*, Wei-qing Liu, Dong-sheng Du, and Wei-zhi Xu \\ College of Civil Engineering, Nanjing Tech University, Jiangsu, Nanjing, 211816, China
}

(c) KSSC and Springer 2018

Erratum to: International Journal of Steel Structures 17(4): 1585-1597 (2017) DOI 10.1007/s13296-017-1224-7

\footnotetext{
Zhen-yuan Gu, Shu-guang Wang*, Wei-qing Liu, Dong-sheng Du, and Wei-zhi Xu

College of Civil Engineering, Nanjing Tech University, Jiangsu, Nanjing, 211816, China

The above authors' information should be as following:

Zhen-yuan $\mathrm{Gu}^{1,2}$, Shu-guang Wang ${ }^{2 *}$, Wei-qing $\mathrm{Liu}^{2}$, Dong-sheng $\mathrm{Du}^{2}$, and Wei-zhi $\mathrm{Xu}^{2}$

${ }^{1}$ School of Civil Engineering and Architecture, Nantong University, 226019, China

${ }^{2}$ College of Civil Engineering, Nanjing Tech University, 211816, China
}

published online March 31, 2018

(C) KSSC and Springer 2018

\footnotetext{
*Corresponding author

Tel: +86-02558139865, Fax: +86-02558139862

E-mail: 720108@vip.sina.com
} 